\title{
Anemia and Its Associated Factors Among Type 2 Diabetes Mellitus Patients Attending Debre Berhan Referral Hospital, North-East Ethiopia: A Cross-Sectional Study
}

This article was published in the following Dove Press journal:

Journal of Blood Medicine

\section{Mitku Mammo Taderegew ${ }^{\prime}$ \\ Tewodros Gebremariam² \\ Amare Abera Tareke $\mathbb{D}^{2}$ \\ Gashaw Garedew \\ Woldeamanuel (D)}

'Department of Biomedical Sciences, College of Medicine and Health Sciences, Wolkite University, Wolkite, Ethiopia; ${ }^{2}$ Department of Biomedical Sciences, Institute of Health, Jimma University, Jimma, Ethiopia
Correspondence: Mitku Mammo Taderegew Department of Biomedical Sciences, College of Medicine and Health Sciences, Wolkite University, P.O. Box 07, Wolkite, Ethiopia Tel +251 923163951

Emailmitkumamo@gmail.com

\begin{abstract}
Purpose: Anemia is one of the common complications of diabetes mellitus (DM), which has an adverse effect on the progression and development of other diabetes-related complications. In spite of this, relatively little information is available on the prevalence of anemia and associated factors among type 2 diabetes mellitus (T2DM) patients in Ethiopia, particularly in the study area. Thus, this study assessed the prevalence of anemia and associated factors among T2DM patients at Debre Berhan Referral Hospital (DBRH), North-East, Ethiopia.
\end{abstract}

Patients and Methods: A hospital-based cross-sectional study was conducted from April 1 to May 30, 2019, among 249 T2DM patients with follow up at DBRH, selected using a systematic random sampling technique. Data were collected by face-to-face interviews, anthropometric measurements, and laboratory tests; such as hemoglobin measurements, red blood indices, and serum creatinine analysis. The data were coded and entered into Epi-data manager version 4.4.1.0, and analysis by using SPSS version 22 was carried out. To identify the determinant factors of anemia, bivariate and multivariate logistic regression analyses were performed. P-value $<0.05$ was considered as statistically significant.

Results: The study showed $20.1 \%$ of the participants were anemic. Being age $>60$ years $(\mathrm{AOR}=3.06,95 \%$ CI: $1.32-7.11)$, poor glycemic control (AOR=2.95, 95\% CI: $1.22-7.15)$, eGFR 60-89.9 $\mathrm{mL} / \mathrm{min} / 1.73 \mathrm{~m}^{2} \quad(\mathrm{AOR}=2.91,95 \% \quad \mathrm{CI}: \quad 1.15-7.37), \quad$ eGFR $<60 \mathrm{~mL} / \mathrm{min} / 1.73 \mathrm{~m}^{2}$ $(\mathrm{AOR}=6.58,95 \% \mathrm{CI}: 2.42-17.93), \mathrm{DM}$ duration $>10$ years $(\mathrm{AOR}=\mathrm{AOR}=2.75,95 \% \mathrm{CI}$ : 1.17-6.48), and having diabetic complications ( $\mathrm{AOR}=3.81,95 \% \mathrm{CI}: 1.65-8.81$ ) were significantly associated with anemia.

Conclusion: One out of five T2DM patients had anemia. Poor glycemic control, decreased eGFR, presence of DM complications, duration of DM $>10$ years, and age $>60$ years were significantly associated with the occurrence of anemia among T2DM. Regular screening for anemia in all T2DM patients may help in the early detection and management of anemia.

Keywords: type 2 DM, anemia, associated factors, Ethiopia

\section{Introduction}

Diabetes mellitus (DM) is a group of metabolic disorder with various etiologies characterized by chronic high blood glucose levels as results of carbohydrate, fat, and protein metabolism disturbances. ${ }^{1}$

Globally, above 400 million adults live with DM, a disease, which caused 1.6 million mortality in $2015 .^{2}$ The number of people with DM in the world is estimated 
to increase from 382 million in 2010, to 592 million in 2035 , and one among ten of the world's population could be affected by diabetes, by the year $2035 .^{3}$

The T2DM accounts for 90-95\% of all DM and affects about $7 \%$ of the general population. ${ }^{1}$ T2DM has increased at a rapid rate and becomes a serious health problem globally, ${ }^{1,4}$ and its occurrence is on the rise, especially in middle-income and low-income countries. ${ }^{5}$

The chronic hyperglycemia of diabetes, especially when poorly controlled, causes long-term damage, dysfunction, and failure of different organs of the body like the eyes, kidneys, nerves, blood, and blood vessels. ${ }^{6}$ Anemia is one of the commonest and prevalent blood-related disorder occurs in patients with diabetes. ${ }^{7}$ It mostly occurs in DM patients who also have renal impairment. ${ }^{8,9}$ Evidence indicates that the existence of anemia among T2DM is typically associated with the failure of the kidney to produce appropriate erythropoietin. ${ }^{10-13}$ The risk of occurring anemia among DM patients with kidney disease is higher and occurs earlier than in those patients with the same level of renal impairment from other etiologies. ${ }^{8,9,14}$ Nevertheless, the early occurrence of anemia in DM patients without renal impairment, ${ }^{15}$ and the occurrence of more frequent and more severe anemia in DM patients compared with patients with the same level of renal impairment from other causes, ${ }^{9,14,15}$ highlights the presence of some other causes of anemia in these patients. ${ }^{15}$

Diabetic neuropathy, chronic inflammatory activity, increased levels of advanced glycation end products (AGEs), erythropoietin hypo-responsiveness, effects of oxidative stress, and anti-diabetic medications are other possible cause of anemia in DM patients. ${ }^{6,16-20}$

Results from many studies showed in the diabetic clinics, the prevalence of unrecognized anemia is nearly two to three folds greater than the general population. In addition, DM patients tend to develop anemia at earlier ages and with greater severity than the general population, putting these patients at greater risk of complications, and this additional burden greatly contributes to patient's comorbid vascular disease and adverse outcomes. ${ }^{21-26}$

The prevalence of anemia among T2DM patients varies in different areas; up to $20 \%$ in Australia, ${ }^{27} 46.5 \%$ in Caribbean population, ${ }^{28} 41.7-63 \%$ in Pakistan, ${ }^{29,30} 41.4 \%$ in Cameroon, ${ }^{31} 29.8 \%$ in Ethiopia, ${ }^{32}$ and $63 \%$ in Egypt. ${ }^{33}$

Anemia in DM patients is a common and often neglected and untreated complication of diabetes, which may have a negative consequence on the development and progression of other diabetes-related macrovascular and microvascular complications which can further enhance anemia progression, making the vicious cycle. ${ }^{34}$ Growing evidence indicates that anemia in T2DM patients is a strong and independent indicator of increased risk for diabetes-related macrovascular and microvascular complications. ${ }^{10,35-38}$ It causes early occurrence and rapid progression of complications like diabetic nephropathy, diabetic retinopathy, diabetic neuropathy, end-stage renal diseases, ischemic heart disease, and nonhealing diabetic foot ulcers. ${ }^{35}$

As in Ethiopia with an increasing incidence of $\mathrm{DM},{ }^{39}$ it becomes mandatory to be aware of such co-morbidities at the earliest. Despite these facts, information on the prevalence of anemia and its associated factors among DM patients is very few in sub-Saharan African countries, including Ethiopia, where other additional potential contributory factors like nutritional deficiencies as well as infectious diseases are very common and expected to worsen the burden of anemia.

This study will provide important information concerning the burden of anemia and its associated factors among T2DM, used as baseline data for further investigation and will be helpful for policymakers, and other stakeholders to develop interventions that on emphasize on routine screening, and proper management of anemia among T2DM patients. Hence, this study was undertaken to determine the prevalence of anemia and its associated factors among T2DM patients at Debre Berhan Referral Hospital.

\section{Materials and Methods}

Hospital-based cross-sectional study was conducted among T2DM patients at DM follow up clinics at Debre Berhan Referral Hospital (DBRH) in North-East Ethiopia, over a period of two months (April 1 to May 30/2019). DBRH is located in Debre Berhan town of Amhara Regional state, about 130 kilometers North-East of Addis Ababa on the main road to Dessie, and has an elevation of 2840 meters above sea level. Currently, DBRH is the only public Hospital in Debre Berhan Town, it serves for 2.8 million catchment population. ${ }^{40}$ There are different units and clinics that provide service for clients. Among these clinics, the diabetes clinic registers, treat and provide care for all diagnosed diabetic patients.

A total of 249 T2DM patients with more than six months' follow-up at the diabetic clinic were included in the study by using a systematic random sampling technique. All adult T2DM patients ( $\geq 18$ years) attending the diabetes clinic in the study periods were considered in the study. Patients with known hematological diseases, patients who had a history of 
delivery within 3 months before the data collection period and, pregnant women, those who were critically ill, and those patients with a history of acute or chronic blood loss and blood transfusion within 3 months of enrollment were excluded. Patients were also excluded if they were known chronic liver disease (CLD) patients, human immunodeficiency virus infection, and malignancy including hematological malignancies.

Sample size was calculated using a single population proportion formula, taking $\mathrm{p}=29.8 \%$ (anticipated proportion of anemia in T2DM), ${ }^{32} 5 \%$ tolerable margin of error $(\mathrm{d}=0.05)$ and confidence interval $(\mathrm{CI})$ of $95 \%(\mathrm{Z} \mathrm{a} / 2$ 1.96). Then the minimum sample size obtained was 321. A correction formula was employed and became 226. By adding 10\% non-response rate, a total of 249 T2DM patients were included in the study. To select the study participants, a systematic random sampling technique (i.e., every third patient) was used.

Data were collected by using semi-structured questionnaire. Three data collectors (one nurse and two laboratory professionals) were collect the data. The collected information includes socio-demographic characteristics, clinical characteristics, anthropometric measurements, and laboratory analysis. Socio-demographic data and clinical characteristics like duration of DM were collected using an interview guide; whereas the presence of diabetes-related complications like; retinopathy, neuropathy, nephropathy, and other complication; history of hypertension and current diabetic medications were collected from reviewing of patient's medical records. Four consecutive fasting blood glucose measurements, including measurement at the time of the data collection period were also recorded from the patient's medical records for calculating the mean blood glucose level.

Anthropometric measurements such as weight $(\mathrm{kg})$, height (m), and waist circumference were measured according to WHO recommendations. The body mass index (BMI) was computed as weight in kilograms divided by the square of the height in meters $\left(\mathrm{kg} / \mathrm{m}^{2}\right)$. The BMI of the participants were classified as: underweight less than $18.5 \mathrm{~kg} / \mathrm{m}^{2}$, normal (18.5-24.9 kg/m²), overweight (25-29.9 kg/m²), and obese ( $\geq$ $\left.30 \mathrm{~kg} / \mathrm{m}^{2}\right) .{ }^{41}$ Central obesity as measured by waist circumference is defined as $>102 \mathrm{~cm}$ in males and $>88 \mathrm{~cm}$ in females. ${ }^{42}$ Blood pressure (BP) was measured using an aneroid sphygmomanometer after 10 mins of rest in a sitting position. Hypertension was defined as Systolic Blood Pressure (SBP) $\geq 130 \mathrm{mmHg}$ and/or Diastolic Blood Pressure (DBP) $\geq 80$ $\mathrm{mmHg}$ or current use of antihypertensive medication.
For laboratory data, from each participant six $\mathrm{mL}$ of venous blood was collected under aseptic conditions by venous puncture from the vein using a disposable syringe as follows: $3 \mathrm{~mL}$ into ethylene diamine tetraacetate (EDTA) tube for hemoglobin and red blood cell (RBC) indices determination, and the remaining $3 \mathrm{~mL}$ into a plain tube for serum creatinine analysis. Hemoglobin $(\mathrm{Hgb})$ values and $\mathrm{RBC}$ indices (MCV, $\mathrm{MCH}$, and $\mathrm{MCHC}$ ) were calculated using the ABX Micros 60 Hematology Analyzer (HoribaABX, Montpellier, France). For serum creatinine analysis, the remaining $3 \mathrm{~mL}$ of blood was collected in a clot activator with a gel test tube and allowed to clot at room temperature for 30 mins. After complete coagulation, the cells were separated from the serum by centrifugation at 3000 RPM for 5 mins. Then serum creatinine was determined using ECHO XPC automatic chemistry analyzer (Edif instruments, Italy) as $\mathrm{mg} / \mathrm{dl}$.

World Health Organization (WHO) criteria was used to define anemia as: Hgb concentration $<13 \mathrm{~g} / \mathrm{dl}$ for males and $<12 \mathrm{~g} / \mathrm{dl}$ for females. ${ }^{43}$ It was further classified into mild anemia (female: 11-11.9 g/dl; male: 11-12.9 g/dl), moderate anemia $(8-10.9 \mathrm{~g} / \mathrm{dl})$ and severe anemia $(<8 \mathrm{~g} /$ dl). ${ }^{44}$ Microcytic was defined as MCV $<80 \mathrm{fl}$, macrocytic: $\mathrm{MCV}>100 \mathrm{fl}$ and hypochromic: $\mathrm{MCHC}$ value $<31 \mathrm{~g} / \mathrm{dl}^{29}$ Serum creatinine values were considered as abnormal if values of serum creatinine analysis were $>1.5 \mathrm{mg} / \mathrm{dl}$ for males and $>1.3 \mathrm{mg} / \mathrm{dl}$ for females. ${ }^{45}$ Good glycemic control: an average of four consecutive fasting blood glucose measurement was $\leq 130 \mathrm{mg} / \mathrm{dl}$ and Poor glycemic control: an average of four consecutive fasting blood glucose measurement was $>130 \mathrm{mg} / \mathrm{dl}^{46}$

Kidney function was estimated by using the simplified version of the Modification of Diet in Renal Disease $(\mathrm{MDRD})$ study equation: $186 \times \mathrm{SCr}(\mathrm{mg} / \mathrm{dl})^{-1.154} \times$ age (years) ${ }^{-0.203} \times 0.742$ (if female) $\times 1.210$ (as the study participants are black). Based on the result, it was classified as normal or increased estimated glomerular filtration rate $\left(\mathrm{eGFR} \geq 90 \mathrm{~mL} / \mathrm{min} / 1.73 \mathrm{~m}^{2}\right)$, mild renal impairment (eGFR 60-89.9 $\mathrm{mL} / \mathrm{min} / 1.73 \mathrm{~m}^{2}$ ), moderate and severe renal impairments $(\mathrm{eGFR}<60 \mathrm{~mL} / \mathrm{min} / 1.73 \mathrm{~m} 2){ }^{47}$

To ensure good data quality, the questionnaire was pretested on $5 \%$ of the actual sample size on those people who did not participate in the study, training was given for data collectors, physical measurements were recorded three times, and close follow-up of the data collection process was carried out. Blood sample quality was also ensured during pre-analytical, analytical, and post-analytical stages by following the standard operating procedures. 
Before entry, data were cleaned and checked; for any missing values. Then, it entered into Epi-data manager version 4.4.1.0 and was exported to SPSS version 22 statistical software for analysis. Then the data were processed by using descriptive analysis like frequency distribution, crosstabulation, and summary measures. Multivariate logistic regression analysis (backward stepwise) was carried out for the selected variables with p-value $<0.25$ in the bivariate logistic regression analysis and the corresponding adjusted odds ratios (AOR) with 95\% confidence intervals (CI) were used to identify factors independently associated with anemia. P-value with $<0.05$ was considered as statistically significant.

\section{Results}

\section{Demographic Characteristics of the Participants}

A total of 249 T2DM patients, of which 128(51.4\%) were females included in the study. Their ages ranged from 36 to 80 years with a mean $( \pm \mathrm{SD})$ of $53.71 \pm 10.41$ years. More than half of the participants, $132(53 \%)$ were aged 45 to 60 years. From the total of the respondents, $172(69.1 \%)$ were married while $31(12.4 \%)$ were single, and $46(18.4 \%)$ were divorced and widowed. One hundred seventy-two (69.1\%) of the participants were from urban areas. About $71(28.5 \%)$ of the respondents had a higher educational status. Regarding the employment status of the participants, $104(41.8 \%)$ were a government employee and 45 (18.1\%) employed at a private organization (Table 1).

\section{Clinical Characteristics of the Participants}

The duration of DM was ranged from 8 months up to 24 years, with a mean $( \pm \mathrm{SD})$ of $7.49 \pm 4.6$ years. From the total of the respondents, $102(41 \%)$ were with less than five years' duration of DM, followed by 84 (33.7\%) from five to ten years. The result of BMI of the patients at the time of study indicated that $162(65.1 \%)$ and $76(30.5 \%)$ of them had normal BMI $\left(18.5-24.9 \mathrm{Kg} / \mathrm{m}^{2}\right)$ and higher BMI ( $\geq 25 \mathrm{~kg} / \mathrm{m}^{2}$ ), respectively. Seventy-eight (31.3\%) of participants presented with documented records of at least one of the diabetes-related microvascular complications. Retinopathy 33 (13.3\%) was the most prevalent complication followed by diabetic nephropathy 15 (6\%), diabetesrelated foot ulcer $14(5.6 \%)$, neuropathy $6(2.4 \%)$, and with more than one complications $10(4 \%)$. Eighty-three (33.3\%) of the participants were hypertensive, with 77 $(30.9 \%)$ and $63(25.3 \%)$ of participants SBP of $\geq 130$ $\mathrm{mmHg}$ and $\mathrm{DBP}$ of $\geq 80 \mathrm{mmHg}$, respectively. The average
Table I Socio-Demographic Characteristics of T2DM Patients at Debre Berhan Referral Hospital, North-East Ethiopia, 2019 $(n=249)$

\begin{tabular}{|c|c|c|c|}
\hline Variable & & $\begin{array}{l}\text { Frequency } \\
(n=249)\end{array}$ & $\begin{array}{l}\text { Percentage } \\
\text { (\%) }\end{array}$ \\
\hline Sex & $\begin{array}{l}\text { Male } \\
\text { Female }\end{array}$ & $\begin{array}{l}121 \\
128\end{array}$ & $\begin{array}{l}48.6 \\
51.4\end{array}$ \\
\hline Age (years) & $\begin{array}{l}<45 \\
45-60 \\
>60\end{array}$ & $\begin{array}{l}58 \\
132 \\
59\end{array}$ & $\begin{array}{l}23.3 \\
53.0 \\
23.7\end{array}$ \\
\hline Marital Status & $\begin{array}{l}\text { Single } \\
\text { Married } \\
\text { Divorced } \\
\text { Widowed }\end{array}$ & $\begin{array}{l}31 \\
172 \\
21 \\
25\end{array}$ & $\begin{array}{l}12.5 \\
69.1 \\
8.4 \\
10.0\end{array}$ \\
\hline $\begin{array}{l}\text { Educational } \\
\text { status }\end{array}$ & $\begin{array}{l}\text { No formal } \\
\text { education } \\
\text { Primary school } \\
(1-8) \\
\text { High school (9-12) } \\
\text { Higher education }\end{array}$ & $\begin{array}{l}65 \\
55 \\
58 \\
71\end{array}$ & $\begin{array}{l}26.1 \\
22.1 \\
23.3 \\
28.5\end{array}$ \\
\hline $\begin{array}{l}\text { Employment } \\
\text { status }\end{array}$ & $\begin{array}{l}\text { Farmer } \\
\text { Housewife } \\
\text { Government } \\
\text { employee } \\
\text { At private } \\
\text { organization } \\
\text { Others* }\end{array}$ & $\begin{array}{l}60 \\
34 \\
104 \\
45 \\
6\end{array}$ & $\begin{array}{l}24.1 \\
13.6 \\
41.8 \\
18.1 \\
2.4\end{array}$ \\
\hline Residence & $\begin{array}{l}\text { Urban } \\
\text { Rural }\end{array}$ & $\begin{array}{l}172 \\
77\end{array}$ & $\begin{array}{l}69.1 \\
30.9\end{array}$ \\
\hline
\end{tabular}

Note: *Others: Unemployed and students.

of four consecutive fasting blood glucose levels (FBG) including FBG during study periods ranged between $101.25-264.25 \mathrm{mg} / \mathrm{dl}$ with a mean $( \pm \mathrm{SD})$ of 147.90 $\pm 35.21 \mathrm{mg} / \mathrm{dl}$. More than half $(54.2 \%)$ of the participants were presented with the level of poor glycemic control.

The majority $(85.1 \%)$ of the participants had normal serum creatinine levels. The mean estimated GFR was, $95.63 \pm 26.2 \mathrm{~mL} / \mathrm{min} / 1.73 \mathrm{~m}^{2}$. One hundred fifty-seven (63.1\%) of the study participants had eGFR $>90 \mathrm{~mL} / \mathrm{min} /$ $1.73 \mathrm{~m}^{2}$ whereas $43(17.3 \%)$ of participants were found with eGFR of $<60 \mathrm{~mL} / \mathrm{min} / 1.73 \mathrm{~m}^{2}$ (Table 2).

\section{Prevalence of Anemia Among T2DM Patients}

The hemoglobin level of the participants was, from $9.4 \mathrm{~g} /$ dl to $17.5 \mathrm{~g} / \mathrm{dl}$, with a mean $( \pm \mathrm{SD})$ of $14.32 \pm 1.68 \mathrm{~g} / \mathrm{dl}$. The mean $( \pm \mathrm{SD})$ of hemoglobin was $14.73 \pm 1.53 \mathrm{~g} / \mathrm{dl}$ and 
Table 2 Clinical Characteristics of the Study Participants at Debre Berhan Referral Hospital, North-East Ethiopia, 2019 $(n=249)$

\begin{tabular}{|c|c|c|c|}
\hline Variables & & $\begin{array}{l}\text { Frequency } \\
(n=249)\end{array}$ & $\begin{array}{l}\text { Percentage } \\
\text { (\%) }\end{array}$ \\
\hline Duration of DM (years) & $\begin{array}{l}<5 \\
5-10 \\
>10\end{array}$ & $\begin{array}{l}102 \\
84 \\
63\end{array}$ & $\begin{array}{l}41.0 \\
33.7 \\
25.3\end{array}$ \\
\hline BMI $\left(\mathrm{Kg} / \mathrm{m}^{2}\right)$ & $\begin{array}{l}\text { Below } 18.5 \\
18.5-24.9 \\
25 \text { and above }\end{array}$ & $\begin{array}{l}11 \\
162 \\
76\end{array}$ & $\begin{array}{l}4.4 \\
65.1 \\
30.5\end{array}$ \\
\hline Central obesity & $\begin{array}{l}\text { Yes } \\
\text { No }\end{array}$ & $\begin{array}{l}45 \\
204\end{array}$ & $\begin{array}{l}18.1 \\
81.9\end{array}$ \\
\hline Hypertension & $\begin{array}{l}\text { Yes } \\
\text { No }\end{array}$ & $\begin{array}{l}83 \\
166\end{array}$ & $\begin{array}{l}33.3 \\
66.7\end{array}$ \\
\hline $\mathrm{SBP}(\mathrm{mmHg})$ & $\begin{array}{l}\geq 130 \\
<130\end{array}$ & $\begin{array}{l}77 \\
172\end{array}$ & $\begin{array}{l}30.9 \\
69.1\end{array}$ \\
\hline $\mathrm{DBP}(\mathrm{mmHg})$ & $\begin{array}{l}\geq 80 \\
<80\end{array}$ & $\begin{array}{l}63 \\
186\end{array}$ & $\begin{array}{l}25.3 \\
74.7\end{array}$ \\
\hline Serum creatinine level & $\begin{array}{l}\text { High } \\
\text { Normal }\end{array}$ & $\begin{array}{l}37 \\
212\end{array}$ & $\begin{array}{l}14.9 \\
85.1\end{array}$ \\
\hline Complications of DM & $\begin{array}{l}\text { Yes } \\
\text { No }\end{array}$ & $\begin{array}{l}78 \\
171\end{array}$ & $\begin{array}{l}31.3 \\
68.7\end{array}$ \\
\hline Glycemic control & $\begin{array}{l}\text { Poor } \\
\text { Good }\end{array}$ & $\begin{array}{l}135 \\
114\end{array}$ & $\begin{array}{l}54.2 \\
45.8\end{array}$ \\
\hline Types of treatment & $\begin{array}{l}\text { Oral } \\
\text { hypoglycemic } \\
\text { agents } \\
{ }^{*} \text { Combined }\end{array}$ & $\begin{array}{l}191 \\
58\end{array}$ & $\begin{array}{l}76.7 \\
23.3\end{array}$ \\
\hline eGFR $\left(\mathrm{mL} / \mathrm{min} / 1.73 \mathrm{~m}^{2}\right)$ & $\begin{array}{l}>90 \\
60-89.9 \\
<60\end{array}$ & $\begin{array}{l}157 \\
49 \\
43\end{array}$ & $\begin{array}{l}63.1 \\
19.7 \\
17.2\end{array}$ \\
\hline
\end{tabular}

Note: *Combined: Both insulin and Oral hypoglycemic agents.

$13.93 \pm 1.73 \mathrm{~g} / \mathrm{dl}$ in male and female participants, respectively. The overall prevalence of anemia in the study participants was found to be $20.1 \%(95 \%$ CI $=15.3-$ $25.3 \%)$; with $23(19.01 \%)$ in males, and $27(21.1 \%)$ in females. The mean $( \pm \mathrm{SD})$ of $\mathrm{Hb}$ levels for males and females anemic patients were $12.2 \pm 0.73 \mathrm{~g} / \mathrm{dl}$ and 11.4 $\pm 0.58 \mathrm{~g} / \mathrm{dl}$, respectively. Out of anemic T2DM patients, $42(84 \%)$ and $8(16 \%)$ had mild and moderate anemia, respectively. Severe anemia was not detected in this study. From these anemic patients, none of them was ever screened for anemia (Figure 1).

The mean $( \pm \mathrm{SD})$ of MCV was $92.5 \pm 5.2 \mathrm{fL}$ and 91.6 $\pm 4.9 \mathrm{fL}$ in anemic and non-anemic patients, respectively.
Likewise, the mean MCHC $( \pm \mathrm{SD})$ was $33.9 \pm 1.6 \mathrm{~g} / \mathrm{dl}$ and $34.2 \pm 1.6 \mathrm{~g} / \mathrm{dl}$ in anemic and non-anemic patients, respectively. The differences in the distribution of both MCV and $\mathrm{MCHC}$ in non-anemic and anemic groups were not statistically significant $(\mathrm{p}>0.05)$.

The majority of anemic patients, 42 (84\%) had MCV between 80-100 fL, and 45 (90\%) of anemic patients had MCHC above $32 \mathrm{~g} / \mathrm{dl}$. Overall 42 (84\%) of patients had normocytic normochromic, $3(6 \%)$ had microcytic hypochromic, and $5(10 \%)$ macrocytic anemia (Figure 2).

\section{Factors Associated with Anemia Among T2DM Patients}

To evaluate the association of each independent variable with the occurrence of anemia, binary logistic regression was performed between the occurrence of anemia (dependent variable) and selected factors (independent variable). To identify the most significant determinant of anemia, factors that showed a $p$-value $\leq 0.25$ in the bivariable analysis were a candidate to the multivariate logistic regression model. In multiple logistic regression analysis, patients with age $>60$ years $(\mathrm{AOR}=3.06$, 95\% CI: 1.32-7.11), poor glycemic control ( $\mathrm{AOR}=2.95,95 \%$ CI: $1.22-7.15)$, duration of $\mathrm{DM}>10$ years $(\mathrm{AOR}=2.75,95 \%$ CI: $1.17-6.48)$, diabetic complications ( $\mathrm{AOR}=3.81,95 \% \mathrm{CI}$ : 1.65-8.81), eGFR $60-89.9 \mathrm{~mL} / \mathrm{min} / 1.73 \mathrm{~m}^{2}$ (AOR $=2.91,95 \%$ CI: $1.15-7.37)$, eGFR $<60 \mathrm{~mL} / \mathrm{min} / 1.73 \mathrm{~m}^{2}$ (AOR $=6.58,95 \%$ CI: 2.42-17.93), were significantly associated with the occurrence of anemia (Table 3 ).

\section{Discussion}

In this institutional-based cross-sectional study, the prevalence of anemia and its associated factors among T2DM patients at Debre Berhan Referral Hospital, North-East Ethiopia, has been assessed. It was found that one out of five T2DM patients had anemia. It is also found that the prevalence of anemia was significantly associated with the different stages of renal function as evidenced by eGFR, age of the patients, duration of DM, level of glycemic control, and presence of diabetes-related complications.

In this finding, the total prevalence of anemia among T2DM patients was $20.1 \%$ (95\% CI $=15.7-25.3 \%)$. This is in line with the study done in Australia (23.3\%), ${ }^{48}$ China $(22.0 \%),{ }^{26}$ and, Iran $(19.6 \%) .{ }^{24}$ However, this finding was relatively higher than a study conducted by Rani et al, in India $(12.3 \%),{ }^{49}$ and Kuwait $(13 \%) .{ }^{50}$ On the other hand, this finding was relatively lower than a cross-sectional study conducted in Brazil (34.24\%), ${ }^{21}$ Kuwait (29.7\%), ${ }^{35}$ Egypt 


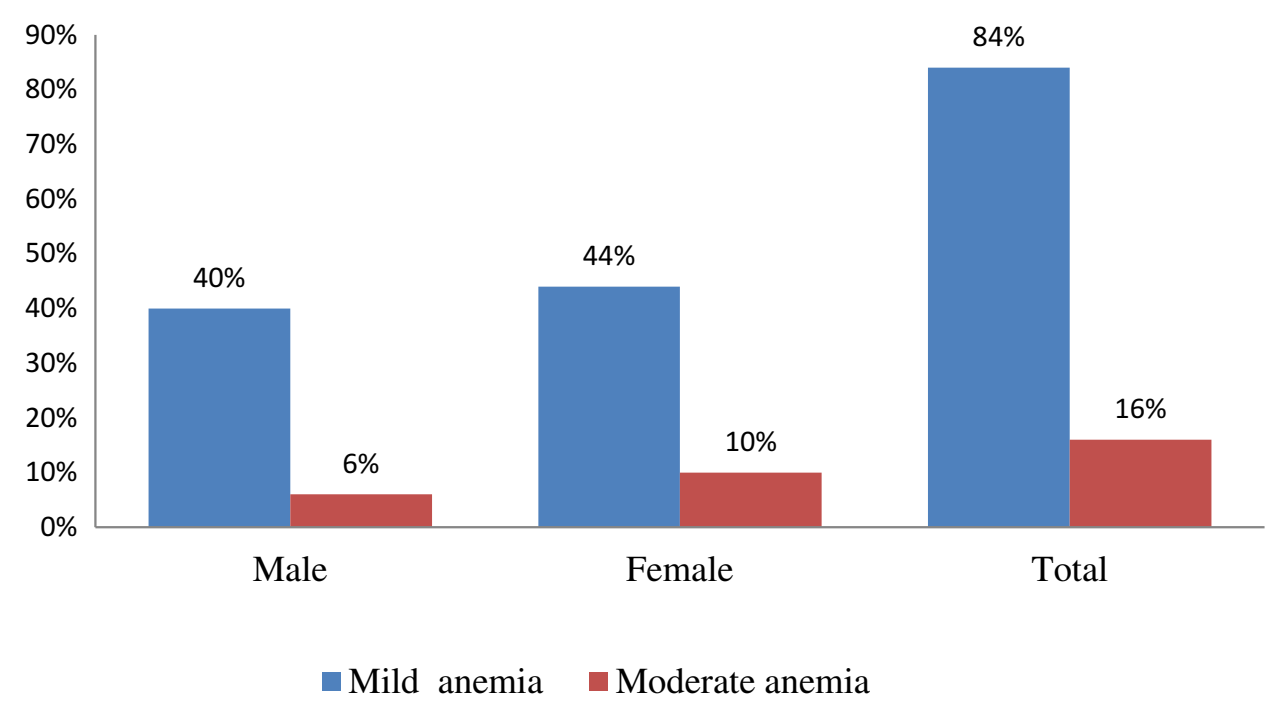

Figure I Prevalence and degree of anemia among type 2 DM patients; attending at Debre Berhan Referral Hospital, North-East Ethiopia, April I - May 30, 2019.

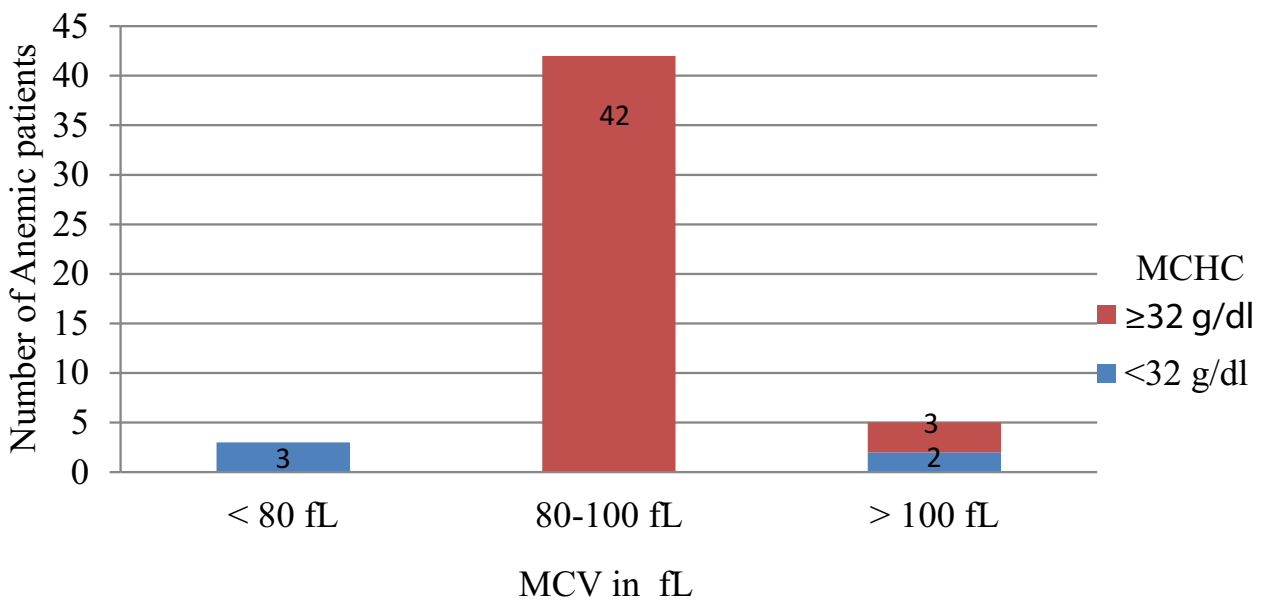

Figure 2 Distribution of MCV and MCHC of anemic type 2 DM patients; attending at Debre Berhan referral hospital, North-East Ethiopia, April I- May $30,2019$.

(63\%), ${ }^{33}$ United Kingdom (59\%), ${ }^{51}$ Caribbean (46.5\%), ${ }^{28}$ Iran $(30.4 \%),{ }^{52}$ Pakistan (63\%), ${ }^{53}$ Malaysia (31.7-39\%), ${ }^{54,55}$ and Fenote Selam Hospital (29.8\%). ${ }^{32}$ These differences might be due to differences in the geographical elevation above sea level, ethnicity, age of the study participants, duration of $\mathrm{DM}$, and the level of development of the country since it affects the quality of health care delivery. ${ }^{6,8,33,43,56}$

The study tried to demonstrate the common morphological characteristics of anemia among T2DM patients. Normocytic normochromic blood picture was the most common morphological types of anemia found in this study. It is not surprising to see normocytic normochromic blood picture of anemia in this study, as various previous studies conducted in China, ${ }^{57}$ Malaysia, ${ }^{54,55}$
India, ${ }^{58,59}$ and Iraq, ${ }^{60}$ also revealed this situation. Since the participants of this study were DM patients, anemia of chronic disease is expected, which is normocytic normochromic in morphology. ${ }^{55,60-62}$ In addition, normocytic normochromic anemia might suggest the significance of the renal origin of anemia in diabetic patients. ${ }^{67,63,64}$ Considering the percentage of anemic patients with altered renal function in this study, the above explanation seems acceptable. Renal impairment leads to anemia though impaired production of erythropoietin by peritubular fibroblast of the kidney, ${ }^{65-67}$ urinary erythropoietin losses, ${ }^{68}$ reduced RBC life span due to uremic environment and the possible role of circulating uremic-induced prevention of erythropoiesis. ${ }^{69,70}$ 
Table 3 Multi-Variable Logistic Regression of Variables Associated with Anemia Among T2DM Patients Attending at Debre Berhan Referral Hospital, North-East Ethiopia, $2019(n=249)$

\begin{tabular}{|c|c|c|c|c|c|c|}
\hline \multirow[t]{2}{*}{ Variable } & \multicolumn{2}{|c|}{ Anemia } & \multirow[t]{2}{*}{ COR $(95 \% \mathrm{Cl})$} & \multirow[t]{2}{*}{ P-value } & \multirow[t]{2}{*}{ AOR $(95 \% \mathrm{Cl})$} & \multirow[t]{2}{*}{ P-value } \\
\hline & Yes & No & & & & \\
\hline \multicolumn{7}{|l|}{ Age category } \\
\hline$\leq 60$ years & 22 & 168 & I* & & $I^{*}$ & \\
\hline$>60$ years & 28 & 31 & $6.89(3.50-13.58)$ & 0.000 & $3.06(1.32-7.1 I)$ & $0.009 * *$ \\
\hline \multicolumn{7}{|l|}{ Duration of DM } \\
\hline$\leq 10$ years & 19 & 166 & $I^{*}$ & & $I^{*}$ & \\
\hline$>10$ years & 31 & 33 & $8.21(4.15-16.24)$ & 0.000 & $2.75(1.17-6.48)$ & $0.021 * *$ \\
\hline \multicolumn{7}{|l|}{ Central obesity } \\
\hline No & 33 & $17 \mid$ & $I^{*}$ & & $I^{*}$ & \\
\hline Yes & 17 & 28 & $3.15(1.55-6.39)$ & 0.002 & $2.54(0.65-9.93)$ & 0.179 \\
\hline \multicolumn{7}{|l|}{ BMI $\left(\mathrm{Kg} / \mathrm{m}^{2}\right)$} \\
\hline $18.5-24.9$ & 27 & 133 & $I^{*}$ & & $I^{*}$ & \\
\hline$<18.5$ & 6 & 10 & $2.96(0.99-8.82)$ & 0.052 & 4.80 (1.09-21.02) & 0.057 \\
\hline$>25$ & 17 & 56 & $1.49(0.75-2.96)$ & 0.248 & $0.98(0.38-2.5 \mathrm{I})$ & 0.976 \\
\hline \multicolumn{7}{|l|}{$\mathrm{SBP}(\mathrm{mmHg})$} \\
\hline$<130$ & 27 & 145 & $I^{*}$ & & $I^{*}$ & \\
\hline$\geq 130$ & 23 & 54 & $2.29(1.21-4.33)$ & 0.011 & $0.48(0.08-2.85)$ & 0.418 \\
\hline \multicolumn{7}{|l|}{$\mathrm{DBP}(\mathrm{mmHg})$} \\
\hline$<80$ & 26 & 160 & $I^{*}$ & & $I^{*}$ & \\
\hline$\geq 80$ & 24 & 39 & $3.79(1.96-7.30)$ & 0.000 & $1.91(0.83-4.39)$ & 0.130 \\
\hline \multicolumn{7}{|l|}{ DM complications } \\
\hline No & 15 & 156 & $I^{*}$ & & $I^{*}$ & \\
\hline Yes & 35 & 43 & $8.47(4.23-16.92)$ & 0.000 & $3.8 I(I .65-8.8 I)$ & $0.002^{* *}$ \\
\hline \multicolumn{7}{|l|}{ Glycemic control } \\
\hline Good & 12 & 102 & $I^{*}$ & & $I^{*}$ & \\
\hline Poor & 38 & 97 & $3.33(1.64-6.75)$ & 0.001 & $2.95(1.22-7.15)$ & $0.017^{* *}$ \\
\hline \multicolumn{7}{|l|}{$\mathrm{SCr}(\mathrm{mg} / \mathrm{dl})$} \\
\hline Normal & 28 & 184 & $I^{*}$ & & $I^{*}$ & \\
\hline Higher & 22 & 15 & $8.28(3.8-17.70)$ & 0.000 & $2.56(0.78-8.4 I)$ & 0.121 \\
\hline \multicolumn{7}{|l|}{ eGFR $\left(\mathrm{mL} / \mathrm{min} / 1.73 \mathrm{~m}^{2}\right)$} \\
\hline$\geq 90$ & 14 & 134 & $I^{*}$ & & $I^{*}$ & \\
\hline $60-89.9$ & 16 & 39 & $3.93(1.76-8.75)$ & 0.001 & $2.91(1.15-7.37)$ & $0.025^{* *}$ \\
\hline$<60$ & 20 & 26 & $7.36(3.30-16.42)$ & 0.000 & $6.58(2.42-17.93)$ & $0.000 * *$ \\
\hline
\end{tabular}

Notes: *References: Category; ${ }^{* * S h o w s ~} \mathrm{p}<0.05=$ significant association with multi-variable logistic regression.

Abbreviation: $\mathrm{SCr}$, Serum creatinine.

However, this study deviates from another study conducted in India, which showed a higher rate of the microcytic hypochromic type of anemia. ${ }^{71}$ The low prevalence of microcytic hypochromic anemia in this study could be explained by their residence and access to health care services. In this study, closer to three-fifth of the participants were from urban areas where health care services related to appropriate nutrition and a variety of nutrition accessible.
Although the study did not assess dietary status, it is unlikely that the anemia was due to nutritional deficiencies since the anemia was normocytic normochromic in the majority (84\%) of patients. Regarding the levels of anemic status, the majority $(84 \%)$ of the respondents had mild anemia; which is also common in anemia of chronic diseases like DM. This study is similar to the finding in Malaysia. $^{54,55}$ 
In this study, there was a statistically significant relation between diabetes-related complications and the occurrence of anemia. As microvascular complications were frequently seen in uncontrolled and long-standing diabetes ${ }^{53}$ the odds ratio of developing anemia in patients with at least one diabetic complication were approximately four times more likely as compared with those without complication.

The study also showed that greater odds for the occurrence of anemia among T2DM patients with age $>60$ years when compared with those of age $\leq 60$ years. Consistent with the present finding, the increased odds ratio for developing anemia has also been found in the previous study conducted in California, ${ }^{56}$ Australia, ${ }^{12}$ China, ${ }^{57}$ Israel, ${ }^{72}$ Nigeria, ${ }^{25}$ and Finote Selam hospital. ${ }^{32}$

In addition, the mean age of anemic participants (62.0 $\pm 10.2)$ is significantly greater than the mean age of nonanemic participants (51.6 \pm 61.4$)$. This result is in-line with a recent study in Kuwait (2018) which showed that old age to be associated with the higher prevalence of anemia in DM patients with the mean age of anemic and non-anemic patients were found to be $60.69 \pm 0.198$ years, $54.07 \pm$ 0.121 years, respectively. ${ }^{35}$ The study conducted in Korea, ${ }^{73}$ and Australia ${ }^{12}$ has also indicated that the prevalence of anemia increases with advancing age. This result was anticipated since aging is related to decreased hemoglobin levels and an increase of anemia irrespective of health status. ${ }^{74,75}$ It also may be related to deficiencies of vitamins such as folate, bone marrow abnormality, and a higher number of co-morbidities, which are common at elderly. ${ }^{73}$

In this finding, the duration of DM is one of the factors associated with the presence of anemia. It was observed that a positive relationship between the duration of DM and anemia with a higher chance in patients with $>10$ years. Compared with patients with $\leq 10$ years duration of DM, the odds ratio of developing anemia in individuals with $>10$ years was approximately three times. This finding is in agreement with the previous studies in Australia, ${ }^{12}$ Korea, ${ }^{76}$ India, ${ }^{49,77}$ and Finote Selam. ${ }^{32}$ The reason for this increased chance of anemia development with an increasing duration of DM may be due to the chronic effects of hyperglycemia. Diabetes-related chronic hyperglycemia can cause a chronic hypoxic milieu in the renal interstitium and disturbance of the interstitial organization or vascular architecture, atypical cell growth and collagen proliferation in tubular cells and peritubular fibroblasts, which cause impaired synthesis of erythropoietin by the peritubular fibroblasts. ${ }^{6,20}$ In addition, in patients with prolonged hyperglycemic conditions, the erythrocyte precursors cells in the bone marrow might be exposed to prolonged direct glucose toxicity leading to disturbances in the erythrocyte production. ${ }^{35}$

This study indicated that the odds of developing anemia among respondents with poor glycemic control were three times more likely as compared with respondents with good glycemic control. This is comparable with findings in Nigeria ${ }^{78}$ India, ${ }^{58}$ Pakistan ${ }^{30}$ and Kuwait. ${ }^{35}$ Because erythropoietin synthesis and release are controlled in part by the autonomic nervous system, ${ }^{22,25}$ and diabetic autonomic neuropathy is common in a condition of poor glycemic control, ${ }^{79,80}$ the results propose that erythropoietin synthesis could be prematurely inhibited in patients with poor glycemic control. In addition, in participants with poorly controlled DM, precursors of erythrocyte in the bone marrow might also be exposed to prolonged direct glucose toxic effects or mature red blood cells can be affected by oxidative stress causing disturbances in the red blood cells function. ${ }^{9}$

Additional factors which have been implicated in the risk of anemia associated with hyperglycemia include; systemic inflammatory damage to renal architecture and consequent formation of AGEs and its effects on bone marrow. ${ }^{10,12,20,22,34,81-83}$ These circumstances may be provoked in poorly controlled diabetes than in controlled diabetes.

This finding showed a considerable relationship between anemia and a decline in eGFR. Out of 50 study participants who were anemic, 36(72\%) showed $<90$ eGFR $\mathrm{mL} / \mathrm{min} / 1.73 \mathrm{~m}^{2}$ and subsequently presented with normochromic normocytic anemia, which is considered to be an indication that the cause of anemia may be due to renal dysfunction. The odds of being anemia in participants with T2DM and mild renal impairments (eGFR $60-89 \mathrm{~mL} / \mathrm{min} / 1.73 \mathrm{~m}^{2}$ ) were roughly three times as compared to participants with normal renal function ( $\geq 90 \mathrm{~mL} / \mathrm{min} / 1.73 \mathrm{~m}^{2}$ ). The odds ratio for developing anemia among participants with $\mathrm{T} 2 \mathrm{DM}$ and moderate renal impairment (eGFR $<60 \mathrm{~mL} / \mathrm{min} / 1.73 \mathrm{~m}^{2}$ ) was also approximately seven times as participants with normal renal function $\left(\geq 90 \mathrm{~mL} / \mathrm{min} / 1.73 \mathrm{~m}^{2}\right)$. The study conducted in Australia, ${ }^{7}$ Finote Selam, ${ }^{32}$ Greece, ${ }^{84}$ and Cameroon, ${ }^{31}$ supported these findings.

Anemia is a well-known complication of diabetesrelated chronic kidney disease (CKD) and related to the degree of renal impairment, mainly due to impaired production of erythropoietin by peritubular fibroblast of the kidney. ${ }^{84}$ The finding in this study further supports this principle, as the results showed a gradually increase in the 
prevalence of anemia with a progressive reduction in renal function. There are many potential mechanisms, by which anemia can exist in patients with reduced renal function tests. Damage to erythropoietin producing cells through either fibrosis or chronic inflammatory activities; tubulointerstitial changes; and autonomic neuropathy, which prevents anemia detection by peritubular fibroblasts of the kidney are the possible mechanism. ${ }^{11,85}$

Even though this study has not attempted to find the cause of anemia, those patients at the highest risk could be recognized by the presence of renal impairment, identified as impaired renal function $<90 \mathrm{~mL} / \mathrm{min} / 1.73 \mathrm{~m}^{2}$ in patients with DM. This indicates that the main cause of anemia may be of the renal origin. Additionally, the occurrences of anemia in patients with DM should direct health professionals to examine the likelihood of renal involvements. ${ }^{7}$

The strength of this study is that it is one of the few studies in developing countries where chronic diseases like DM with associated complications are becoming more common. The study has its limitation as lacks of age and sexmatched control groups; due to the nature of the study design, cause/effect relationship not identified; the dietary pattern was not assessed; $\mathrm{Hb}$ level did not adjusted for altitude; as well as the level of glycemic status was assessed by FBG rather than $\mathrm{HbAlc}$. The other limitation of this study is that the cut off point for anemia used in this study is not validated among adult populations of Ethiopian origin.

\section{Conclusion}

One out of five T2DM patients had anemia, including among those with normal renal function evidenced by eGFR. Most of the anemic patients had a mild type of anemia. Morphologically, the predominant type of anemia was normocytic normochromic anemia.

Poor glycemic control, decreased eGFR, diabetesrelated complications, duration of $\mathrm{DM}>10$ years, and age $>60$ years were significantly associated. The results suggest the necessity for incorporating regular screening for anemia in all T2DM patients mainly for patients with these identified risk factors to facilitate early detection and management of anemia among T2DM and consequently improve the overall care of these patients.

\section{Abbreviations}

AGEs, Advanced Glycation End Products; AOR, Adjusted Odd Ratio; BMI, Body Mass Index; CI, Confidence Interval; CKD, Chronic Kidney Disease; CLD, Chronic Liver Disease; DBP, Diastolic Blood Pressure; DBRH, Debre Berhan Referral
Hospital; DL, Deciliters; DM, Diabetes Mellitus; EDTA, Ethylene Diamine Tetra Acetic Acid; eGFR, Estimated Glomerular Filtration Rate; FBG, Fasting Blood Glucose; FL, Femto Liter; $\mathrm{Hb}$, Hemoglobin; IDF, International Diabetic Federation; MCH, Mean Corpuscular Hemoglobin; MCHC, Mean Corpuscular Hemoglobin Concentration; MCV, Mean Corpuscular Volume; MDRD, Modification of Diet in Renal Disease; OR, Odds Ratio; PG, Pico Gram; RBC, Red Blood Cell; RPM, Revolution Per Minute; SBP, Systolic Blood Pressure; SCr, Serum Creatinine; SD, Standard Deviation; SPSS, Statistical Package for Social Science; WHO, World Health Organization.

\section{Ethics Approval and Informed Consent}

The study was undertaken after the Institutional Review Board (IRB) of the institute of Health, Jimma University, approved the study protocol. Then Permission and supportive letter to carry out the study was also obtained from Debre Berhan Referral Hospital. The study was conducted in accordance with the Declaration of Helsinki, and an informed consent (verbal as well as written) was obtained from each study participants. Confidentiality was maintained by omitting their name; rather the patient's card number was used as patient unique identification number throughout the study and unauthorized persons did not have access to the data. Those patients with anemia, renal insufficiency, and other relevant findings; were linked to physician for proper management.

\section{Data Sharing Statement}

The datasets used and/or analyzed during the current study are available from the corresponding author on reasonable request.

\section{Acknowledgments}

The authors would like to extend their deepest appreciation to all staff member of Diabetic clinic of Debre Berhan Referral Hospital for their collaboration to providing the necessary information for this study. We also would like to thank all the study participants for their cooperation during the study. We are grateful to thank Jimma University for providing financial assistance for the study.

\section{Author Contributions}

All authors contributed to data analysis, drafting or revising the article, gave final approval of the version to be published, and agree to be accountable for all aspects of the work. 


\section{Funding}

This study was funded by Jimma University. The funders had no role in study design, data collection and analysis, decision to publish, or preparation of the manuscript.

\section{Disclosure}

The authors declare that they have no competing interests.

\section{References}

1. American Diabetes Association. Standards of medical care in diabetes - 2017 abridged for primary care providers. Clin Diabetes. 2017;35(1):5. doi:10.2337/cd16-0067

2. World Health Organization. Guidelines on Second-And Third-Line Medicines and Type of Insulin for the Control of Blood Glucose Levels in Non-Pregnant Adults with Diabetes Mellitus. World Health Organization; 2018.

3. Binh TQ, Nhung BT. Prevalence and risk factors of type 2 diabetes in middle-aged women in Northern Vietnam. Int J Diabetes Dev Ctries. 2016;36(2):150-157. doi:10.1007/s13410-015-0372-6

4. Shaw JE, Sicree RA, Zimmet PZ. Global estimates of the prevalence of diabetes for 2010 and 2030. Diabetes Res Clin Pract. 2010;87 (1):4-14. doi:10.1016/j.diabres.2009.10.007

5. Cho N, Shaw JE, Karuranga S, et al. IDF diabetes atlas: global estimates of diabetes prevalence for 2017 and projections for 2045. Diabetes Res Clin Pract. 2018;138:271-281. doi:10.1016/j.diabres.2018.02.023

6. Antwi-Bafour S, Hammond S, Adjei JK, Kyeremeh R, MartinOdoom A, Ekem I. A case-control study of prevalence of anemia among patients with type 2 diabetes. J Med Case Rep. 2016;10 (1):110. doi:10.1186/s13256-016-0889-4

7. Thomas MC, MacIsaac RJ, Tsalamandris C, et al. The burden of anaemia in type 2 diabetes and the role of nephropathy: a cross-sectional audit. Nephrol Dial Transplant. 2004;19(7):1792-1797. doi:10.1093/ndt/ gfh248

8. El-Achkar TM, Ohmit SE, Mccullough PA, et al. Higher prevalence of anemia with diabetes mellitus in moderate kidney insufficiency: the kidney early evaluation program. Kidney Int. 2005;67 (4):1483-1488. doi:10.1111/j.1523-1755.2005.00226.x

9. Mahjoub AR, Patel E, Ali S, Webb K, Astrow A, Kalavar M. Anemia in diabetic patients without underlying nephropathy, a retrospective cohort study. Blood. 2016;24(3):495-499.

10. Thomas MC, Cooper ME, Rossing K, Parving HH. Anaemia in diabetes: is there a rationale to TREAT? Diabetologia. 2006;49 (6):1151. doi:10.1007/s00125-006-0215-6

11. McGill JB, Bell DS. Anemia and the role of erythropoietin in diabetes. J Diabetes Complications. 2006;20(4):262-272. doi:10.1016/j.jdiacomp. 2005.08.001

12. Thomas M, Tsalamandris C, MacIsaac R, Jerums G. Anaemia in diabetes: an emerging complication of microvascular disease. Curr Diabetes Rev. 2005;1(1):107-126. doi:10.2174/1573399052952587

13. Thomas MC. The high prevalence of anemia in diabetes is linked to functional erythropoietin deficiency. Semin Nephrol. 2006;26:275-282. doi:10.1016/j.semnephrol.2006.05.003

14. Astor BC, Muntner P, Levin A, Eustace JA, Coresh J. Association of kidney function with anemia: the Third National Health and Nutrition Examination Survey (1988-1994). Arch Intern Med. 2002;162 (12):1401-1408. doi:10.1001/archinte.162.12.1401

15. Thomas MC, MacIsaac RJ, Tsalamandris C, Power D, Jerums G. Unrecognized anemia in patients with diabetes: a cross-sectional survey. Diabetes Care. 2003;26(4):1164-1169. doi:10.2337/diacare.26.4.1164

16. Craig KJ, Williams JD, Riley SG, et al. Anemia and diabetes in the absence of nephropathy. Diabetes Care. 2005;28(5):1118-1123. doi: $10.2337 /$ diacare.28.5.1118
17. Montemarano N, Guttman J, McFarlane SI. Anemia of chronic kidney disease - a modifiable risk factor in a growing high cardiovascular risk population. Type 2 Diabet. 2013;253-267.

18. Forte V, Kim M, Steuber G, Asad S, McFarlane SI. Anemia of chronic kidney disease in diabetic patients: pathophysiologic insights and implications of recent clinical trials. In: Recent Advances in the Pathogenesis, Prevention and Management of Type 2 Diabetes and its Complications; IntechOpen. 2011:273-282.

19. Baisakhiya S, Garg P, Singh S. Anemia in patients with type II diabetes mellitus with and without diabetic retinopathy. Int J Med Sci Public Health. 2017;6(2):303-306. doi:10.5455/ijmsph.2017.03082016604

20. Singh DK, Winocour P, Farrington K. Erythropoietic stress and anemia in diabetes mellitus. Nat Rev Endocrinol. 2009;5(4):204. doi:10.1038/nrendo.2009.17

21. Barbieri J, Fontela PC, Winkelmann ER, et al. Anemia in patients with type 2 diabetes mellitus. Anemia. 2015. 1-7. doi:10.1155/2015/ 354737

22. Gupta A, Gupta S, Gupta V, Gupta V. Evaluation of incidence of anemia in type 2 diabetic patients with normal renal function. Indian J Pathol Microbiol. 2017;4(1):132-134.

23. Makadiya R, Bhanvadia V, Bhavsar M, et al. Association of anaemia in type $2 \mathrm{DM}$ in patients of Dhiraj General Hospital. Int $J$ Biomed Adv Res. 2013;4(6):410-413. doi:10.7439/ijbar.v4i6.390

24. Bonakdaran S, Gharebaghi M, Vahedian M. Prevalence of anemia in type 2 diabetes and role of renal involvement. Saudi J Kidney Dis Transpl. 2011;22(2):286.

25. Adejumo BI, Dimkpa U, Ewenighi CO, et al. Incidence and risk of anemia in type- 2 diabetic patients in the absence of renal impairment. Health. 2012;4(6):304-308. doi:10.4236/health.2012.46050

26. He BB, Xu M, Wei L, et al. Relationship between anemia and chronic complications in Chinese patients with type 2 diabetes mellitus. Arch Iran Med. 2015;18(5):277. doi:015184/AIM.006

27. Thomas MC, Tsalamandris C, MacIsaac RJ, Jerums G. The epidemiology of hemoglobin levels in patients with type 2 diabetes. $\mathrm{Am}$ j Kidney Dis. 2006;48(4):537-545. doi:10.1053/j.ajkd.2006.06.011

28. Ezenwaka CE, Jones-LeCointe A, Nwagbara E, Seales D, Okali F. Anaemia and kidney dysfunction in caribbean type 2 diabetic patients. Cardiovasc Diabetol. 2008;7(1):25. doi:10.1186/14752840-7-25

29. Ahmed K, Danial K, Khurram A, Wasey MA, Ahmed M, Jangda ZA. To evaluate the renal function deterioration along with other anemia predictors in patients with diabetes mellitus type 2 in Karachi, Pakistan. Pak J Surg. 2017;33(2):135-139.

30. Sharif A, Younus S, Baig K, Ali NH. Prevalence and risk of anemia in type-2 diabetic patients. Health. 2014;6(12):1415. doi:10.4236/ health.2014.612173

31. Feteh VF, Choukem SP, Kengne AP, Nebongo DN, Ngowe-Ngowe $\mathrm{M}$. Anemia in type 2 diabetic patients and correlation with kidney function in a tertiary care sub-Saharan African hospital: a cross-sectional study. BMC Nephrol. 2016;17(1):29. doi:10.1186/ s12882-016-0247-1

32. Abate A, Birhan W, Alemu A. Association of anemia and renal function test among diabetes mellitus patients attending Fenote Selam Hospital, West Gojam, Northwest Ethiopia: a cross sectional study. BMC Hematol. 2013;13(6):1-7. doi:10.1186/2052-1839-13-6

33. Fayed HM, Elsaied AR, Alsenbesy MA, Moubark IA. Proportion of anemia in type 2 diabetic patients in qena governorate Case-Control Study: clinical correlates and prognostic significance. Int $J$ of Diabet Res. 2013;2(4):64-75.

34. Thomas MC. Anemia in diabetes: marker or mediator of microvascular disease? Nat Rev Nephrol. 2007;3(1):20.

35. Samuel TR, Tejaswi N, Kumar P, et al. Clinical significance of screening for anaemia in diabetic patients. Artic Int J Pharm Sci Rev Res. 2018;48(2):20-24.

36. Salma M, AlDallal NJ. Prevalence of anemia in type 2 diabetic patients. J Hematol. 2018;7(2):57-61. doi:10.14740/jh411w 
37. Periasamy S, Xavier AA, Gowtham R. Incidence of anemia in type 2 diabetic mellitus and its prognostic index. Int J Med Res Rev. 2016;4 (7):1239-1242.

38. Holland DC, Lam M. Predictors of hospitalization and death among pre-dialysis patients: a retrospective cohort study. Nephrol Dial Transplant. 2000;15(5):650-658. doi:10.1093/ndt/15.5.650

39. Abebe N, Kebede T, Addise D. Diabetes in Ethiopia 2000-2016 prevalence and related acute and chronic complications; a systematic review. Afr J Diabet Med. 2017;25:2.

40. The Ethiopian Hearald. Ethiopia: Hospital Reform Improving Health Care Service Delivery; 2018. Available from: http://allafrica.com/ stories/201707100519.html. Accessed July 21, 2019.

41. Seidell JC, Flegal KM. Assessing obesity: classification and epidemiology. Br Med Bull. 1997;53(2):238-252. doi:10.1093/ oxfordjournals.bmb.a011611

42. Kiernan M, Winkleby MA. Identifying patients for weight-loss treatment: an empirical evaluation of the NHLBI obesity education initiative expert panel treatment recommendations. Arch Intern Med. 2000;160(14):2169-2176. doi:10.1001/archinte.160.14.2169

43. World Health Organization. Haemoglobin Concentrations for the Diagnosis of Anaemia and Assessment of Severity. World Health Organization; 2011.

44. Paul D, Paul S, Asaduzzaman M, Juliana FM, Hossain MS. Prevalence of type 2 diabetes mellitus patients with anemia in a Bangladeshi population-A Case Control Study. Int J Heal Sci Res. 2017;7(3):121-125.

45. Fiseha T, Mengesha T, Girma R, Kebede E, Gebreweld A. Estimation of renal function in adult outpatients with normal serum creatinine. BMC Res Notes. 2019;12(1):462. doi:10.1186/s13104-019-4487-6

46. Kassahun T, Eshetie T, Gesesew H. Factors associated with glycemic control among adult patients with type 2 diabetes mellitus: a cross-sectional survey in Ethiopia. BMC Res Notes. 2016;9(1):78. doi:10.1186/s13104-016-1896-7

47. Levey AS, Stevens LA, Schmid $\mathrm{CH}$, et al. A new equation to estimate glomerular filtration rate. Ann Intern Med. 2009;150 (9):604-612. doi:10.7326/0003-4819-150-9-200905050-00006

48. Thomas MC, Cooper ME, Tsalamandris C, MacIsaac R, Jerums G. Anemia with impaired erythropoietin response in diabetic patients. Arch Intern Med. 2005;165(4):466-469. doi:10.1001/archinte.165.4.466

49. Ranil PK, Raman R, Rachepalli SR, et al. Anemia and diabetic retinopathy in type 2 diabetes mellitus. J Assoc Physicians India. 2010;58:91-94.

50. Mojiminiyi OA, Abdella NA, Zaki MY, El Gebely SA, Mohamedi HM, Aldhahi WA. Prevalence and associations of low plasma erythropoietin in patients with Type 2 diabetes mellitus. Diabet Med. 2006;23(8):839-844. doi:10.1111/dme.2006.23.issue-8

51. Trevest K, Treadway H, Hawkins-van der Cingel G, Bailey C, Abdelhafiz AH. Prevalence and determinants of anemia in older people with diabetes attending an outpatient clinic: a cross-sectional audit. Clin Diabetes. 2014;32(4):158. doi:10.2337/diaclin.32.4.158

52. Hosseini MS, Rostami Z, Saadat A, Saadatmand SM, Naeimi E. Anemia and microvascular complications in patients with type 2 diabetes mellitus. Nephrourol Mon. 2014;6(4)::1-7. doi:10.5812/numonthly

53. Shams N, Osmani MH. Newly diagnosed anemia in admitted diabetics, frequency, etiology and associated factors. J Coll Physicians Surg Pak. 2015;25(4):242-246. doi:04.2015/JCPSP.242246

54. Idris I, Tohid H, Muhammad NA, et al. Anaemia among primary care patients with type 2 diabetes mellitus (T2DM) and chronic kidney disease (CKD): a multicentred cross-sectional study. BMJ Open. 2018;8(12):1-9. doi:10.1136/bmjopen-2018-025125

55. Thambiah SC, Samsudin IN, George E, et al. Anaemia in type 2 diabetes mellitus (T2DM) patients in Hospital Putrajaya. Malaysian $J$ Med Health Sci. 2015;11(1):49-62.
56. Ahmed AT, Go AS, Warton EM, Parker MM, Karter AJ. Ethnic differences in anemia among patients with diabetes mellitus: the Diabetes Study of Northern California (DISTANCE). Am J Hematol. 2010;85(1):57-61. doi:10.1002/ajh.21577

57. Chen CXR, Li YC, Chan SL, Chan KH. Anaemia and type 2 diabetes: implications from a retrospectively studied primary care case series. Hong Kong Med J. 2013;19(3):214-221. doi:10.12809/ hkmj133814

58. Bhargav K, Baruah K, Kumar Agrawal P, et al. Study of anaemia in type II diabetes mellitus in relation to glycemic control. Int Arch Biomed Clin Res. 2016;2(4):29-33. doi:10.21276/iabcr.2016.2.4.7

59. Puneeth BS, Mural R, Brid NS. Study of hematological profile of anemia in type 2 diabetes mellitus patients. Sch J Appl Med Sci. 2017;5:1070-1073.

60. Abdulqadir AH, Polus RK. Prevalence of anemia of chronic disease and iron deficiency anemia among adult diabetic patients in Erbil City. Zanco J Med Sci. 2014;18(1):674-679. doi:10.15218/zjms.2014.0013

61. Madu AJ, Ughasoro MD. Anaemia of chronic disease: an in-depth review. Med Princ Pract. 2017;26(1):1-9. doi:10.1159/000452104

62. Ida H. Pathogenesis and clinical examination of autoinflammatory syndrome. Rinsho Byori Jpn j Clin Pathol. 2015;63(10):1207-1212.

63. Angelousi A, Larger E. Anaemia, a common but often unrecognized risk in diabetic patients: a review. Diabetes Metab. 2015;41 (1):18-27. doi:10.1016/j.diabet.2014.06.001

64. Aljohani AH, Alrubyyi MA, Alharbi AB, et al. The relation between diabetes type II and anemia. Egypt J Hosp Med. 2018;70(4):526-531. doi: $10.12816 / 0043795$

65. Cullis JO. Diagnosis and management of anaemia of chronic disease: current status. Br J Haematol. 2011;154(3):289-300. doi:10.1111/ j.1365-2141.2011.08741.x

66. Pappa M, Dounousi E, Duni A, Katopodis K. Less known pathophysiological mechanisms of anemia in patients with diabetic nephropathy. Int Urol Nephrol. 2015;47(8):1365-1372. doi:10.1007/ s11255-015-1012-2

67. Ravanan R, Spiro JR, Mathieson PW, Smith RM. Impact of diabetes on haemoglobin levels in renal disease. Diabetologia. 2007;50 (1):26-31. doi:10.1007/s00125-006-0514-y

68. Thomas S, Stevens PE. Anaemia in diabetic kidney disease: an area for improvement? Pract Diabet Int. 2006;23(1):22-26. doi:10.1002/ (ISSN)1528-252X

69. Alsayegh F, Waheedi M, Bayoud T, Al Hubail A, Al-Refaei F, Sharma P. Anemia in diabetes: experience of a single treatment center in Kuwait. Prim Care Diabetes. 2017;11(4):383-388. doi:10.1016/j. pcd.2017.04.002

70. Babitt JL, Lin HY. Mechanisms of anemia in CKD. J Am Soc Nephrol. 2012;23(10):1631-1634. doi:10.1681/ASN.2011111078

71. Kaushik D, Parashar R, Malik PK. Study of anaemia in type 2 diabetes mellitus. Int $J$ Res Med Sci. 2018;6(5):1529-1533. doi:10.18203/2320-6012.ijrms20181428

72. Goldhaber A, Ness-Abramof R, Ellis M. Prevalence of anemia among unselected adults with diabetes mellitus and normal serum creatinine levels. Endoc Pract. 2009;15(7):714-719. doi:10.4158/EP09119.ORR

73. Choi CW, Lee J, Park KH, et al. Prevalence and characteristics of anemia in the elderly: cross-sectional study of three urban Korean population samples. Am J Hematol. 2004;77(1):26-30. doi:10.1002/ (ISSN) 1096-8652

74. Salive ME, Cornoni-Huntley J, Guralnik JM, et al. Anemia and hemoglobin levels in older persons: relationship with age, gender, and health status. $J$ Am Geriatr Soc. 1992;40(5):489-496. doi:10.1111/j.1532-5415.1992.tb02017.x

75. Gaskell H, Derry S, Moore RA, McQuay HJ. Prevalence of anaemia in older persons: systematic review. BMC Geriatr. 2008;8(1):1. doi:10.1186/1471-2318-8-1 
76. Chung JO, Cho DH, Chung DJ, Chung MY. Associations between hemoglobin concentrations and the clinical characteristics of patients with type 2 diabetes. Korean J Intern Med. 2012;27(3):285. doi: 10.3904/kjim.2012.27.3.285

77. Rathod GB, Parmar P, Rathod S, Parikh A. Prevalence of anemia in patients with type 2 diabetes mellitus at Gandhinagar, Gujarat, India. Int Arch Integ Med. 2016;3:12-16.

78. Adejumo BI, Dimkpa U, Ewenighi CO, Erhabor TA. The incidence of anemia and the impact of poor glycemic control in type-2 diabetic patients with renal insufficiency. J Biol Agric Healthcare. 2013;3 (13):130-136.

79. Ahmed AM, Hussein A, Ahmed NH. Diabetic autonomic neurapathy. Saudi Med J. 2000;21(11):1034-1037.

80. Töyry JP, Niskanen LK, Mäntysaari MJ, Länsimies EA, Uusitupa MI. Occurrence, predictors, and clinical significance of autonomic neuropathy in NIDDM: ten-year follow-up from the diagnosis. Diabetes. 1996;45(3):308-315. doi:10.2337/diab.45.3.308
81. Mehdi U, Toto RD. Anemia, diabetes, and chronic kidney disease. Diabetes Care. 2009;32(7):1320-1326. doi:10.2337/dc08-0779

82. Kitada M, Zhang Z, Mima A, GL K. Molecular mechanisms of diabetic vascular complications. J Diabetes Investig. 2010;1(3):77-89. doi:10. 1111/j.2040-1124.2010.00018.x

83. Creager MA, Lüscher TF, Cosentino F, Beckman JA. Diabetes and vascular disease: pathophysiology, clinical consequences, and medical therapy: part I. Circulation. 2003;108(12):1527-1532. doi:10.1161/01. CIR.0000091257.27563.32

84. Loutradis C, Skodra A, Georgianos P, et al. Diabetes mellitus increases the prevalence of anemia in patients with chronic kidney disease: a nested case-control study. World J Nephrol. 2016;5(4):358. doi:10.5527/wjn.v5.i4.358

85. Jones SC, Smith D, Nag S, et al. Prevalence and nature of anaemia in a prospective, population-based sample of people with diabetes: teesside anaemia in diabetes (TAD) study. Diabet Med. 2010;27 (6):655-659. doi:10.1111/dme.2010.27.issue-6

\section{Publish your work in this journal}

The Journal of Blood Medicine is an international, peer-reviewed, open access, online journal publishing laboratory, experimental and clinical aspects of all aspect pertaining to blood based medicine including but not limited to: Transfusion Medicine; Blood collection, Donor issues, Transmittable diseases, and Blood banking logistics; Immunohematology; Artificial and alternative blood based therapeutics; Hematology; Biotechnology/nanotechnology of blood related medicine; Legal aspects of blood medicine; Historical perspectives. The manuscript management system is completely online and includes a very quick and fair peer-review system. Visit http://www.dovepress.com/testimonials.php to read real quotes from published authors. 